\title{
THE STRAIGHT CERVICAL SPINE: DOES IT INDICATE MUSCLE SPASM?
}

\author{
P. S. HELLIWELL, P. F. EVANS, V. WRIGHT \\ From Huddersfield Royal Infirmary and the University Department of Clinical Medicine, Leeds, England
}

The loss of cervical lordosis in radiographs of patients presenting with neck pain is sometimes ascribed to muscle spasm. We performed a cross-sectional study of the prevalence of 'straight' cervical spines in three populations: 83 patients presenting to an accident department with acute neck pain, 83 referred to a radiology department with chronic neck problems, and 80 radiographs from a normal population survey carried out in 1958. Curvature was assessed on lateral radiographs both subjectively and by measurement.

The prevalence of 'straight' cervical spines was 19\% in the acute cases and $26 \%$ in the chronic cases. The $95 \%$ confidence interval for the difference was $-6.4 \%$ to $+19.3 \%$. In the normal population $42 \%$ showed a straight spine, but a further third of these films had been taken in a position of cervical kyphosis; this probably reflects a difference in positioning technique. Women were more likely than men to have a straight cervical spine, with an odds ratio of 2.81 (95\% CI 1.23 to 6.44).

Our results fail to support the hypothesis that loss of cervical lordosis reflects muscle spasm caused by pain in the neck.

J Bone Joint Surg /Br/ 1994; 76-B:103-6. Received 23 March 1993; Accepted after revision 17 June 1993

P. S. Helliwell, DM, MRCP, Consultant Rheumatologist Rheumatology and Rehabilitation Research Unit, 36 Clarendon Road, Leeds LS2 9NZ, UK.

P. F. Evans, FRCS, FRCR, Consultant Radiologist

The Royal Infirmary, Lindley, Huddersfield, West Yorkshire HD3 3EA, UK.

V. Wright, MD, FRCP, ARC Professor of Rheumatology

University Department of Clinical Medicine, Leeds General Infirmary, Great George Street, Leeds LS1 3EX, UK.

Correspondence should be sent to Dr P. S. Helliwell.

(C)1994 British Editorial Society of Bone and Joint Surgery

0301-620X/94/1694\$2.00
Cervical spine radiographs which show loss of cervical lordosis are sometimes interpreted as indicating spasm of the neck muscles, and a similar significance is often placed on loss of lumbar lordosis in cases of low back pain (Cyriax 1978). The stronger extensor muscles, however, would be expected to induce an increase in lordosis in both the lumbar and the cervical spine or a rotational displacement such as is seen in acute torticollis.

The assessment of muscle spasm is difficult, requiring more objective methods than digital palpation. We therefore performed a radiological study of the relationship between loss of cervical lordosis and neck pain. A prospective longitudinal case-controlled study would have been difficult to justify, and so we decided on a cross-sectional study of groups of patients with differing presence and duration of neck pain. Patients with acute neck pain referred for cervical spine radiography from the emergency department were compared with those referred by general practitioners because of chronic neck problems. We assumed that the second group would be less likely to have muscle spasm. We thought it unethical to radiograph a normal control group, and we therefore asked the ARC Epidemiology Unit in Manchester for the Wensleydale and Leigh survey films obtained in 1958 (Lawrence 1969). Our hypothesis was that there would be no difference in the prevalence of loss of cervical lordosis between the three groups.

\section{PATIENTS AND METHODS}

In a pilot study, 29 radiographs of patients referred by general practitioners for chronic neck pain and 22 radiographs of patients who presented to the accident department with acute neck pain were read by two observers (PSH, PFE). Loss of cervical lordosis was found in $17 \%$ of the chronic group (5/29) and $36 \%$ of the acute group (8/22). From these figures we calculated that 80 cases in each group would be required to show that this difference was significant at the $5 \%$ level (power $90 \%$ ).

For the main study, acute cases were randomly selected as every fourth name from a computer print-out, excluding patients under 16 years of age. Of the 380 names available, not all had cervical radiography. Of the 284 chronic cases referred by general practitioners an equivalent number of films were selected, using a similar procedure. The third group, of 'normal' films from the ARC survey, was selected randomly after stratification by age and sex: we obtained 




Fig. 1

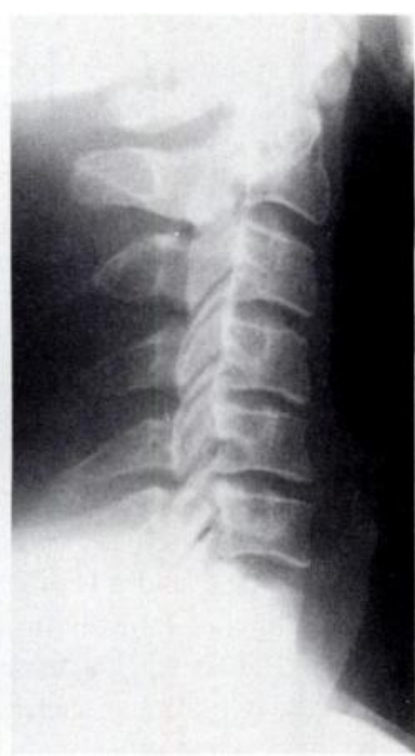

Fig. 2

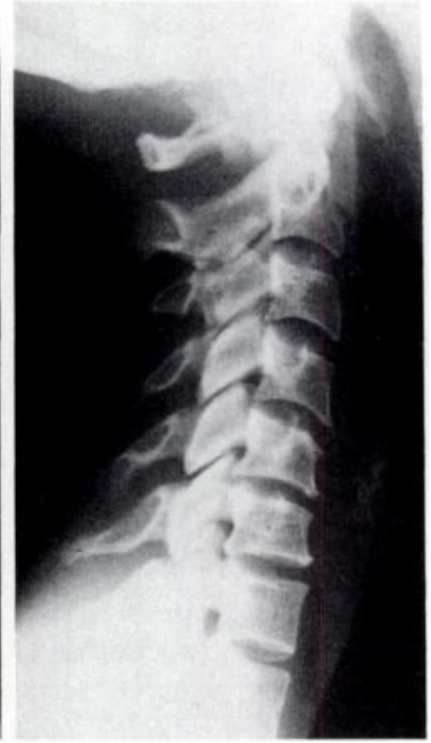

Fig. 3

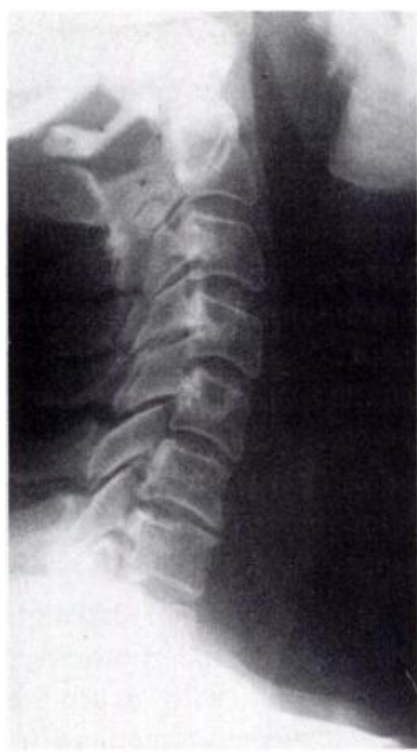

Fig. 4

Figure 1 - Normal cervical lordosis. Figure 2 - Cervical kyphosis. Figure 3-A 'straight' cervical spine. Figure 4 - A 'low straight' cervical spine.

films from ten men and ten women for each of the age ranges 16 to 30 years, 31 to 45,46 to 60 , and 61 or more. Most of these subjects had been asymptomatic at the time they were radiographed.

All films were read independently by two observers (PSH, PFE), and each was recorded as showing one of four shapes for the cervical spine from the body of $\mathrm{C} 2$ to the body of C7: normal lordosis (Fig. 1), kyphosis (Fig. 2), straight (Fig. 3) or 'low straight' where the spine appeared straight from $\mathrm{C} 4$ to $\mathrm{C} 7$ but retained a small lordosis at $\mathrm{C} 2$ to $\mathrm{C} 4$ (Fig. 4). At a later stage the curve was quantified by the method of Batzdorf and Batzdorff (1988), as shown in Figure 5. On each lateral film a line was drawn between the posterior inferior corners of $\mathrm{C} 2$ and $\mathrm{C} 7$. From this line we measured the perpendicular distance to the posterior inferior corners of each of $\mathrm{C} 3$ to $\mathrm{C} 6$, and then calculated the area bounded by the straight line and an arc whose radius was calculated to fit the posterior inferior corners of $\mathrm{C} 3$ to $\mathrm{C} 6$. Cervical curvature was then defined as:

1) kyphosis, $-500 \mathrm{~mm}^{2}$ to $-100 \mathrm{~mm}^{2}$;

2) straight, $-99 \mathrm{~mm}^{2}$ to $+99 \mathrm{~mm}^{2}$;

3) normal, $+100 \mathrm{~mm}^{2}$ to $+499 \mathrm{~mm}^{2}$; and

4) hyperlordotic, $+500 \mathrm{~mm}^{2}$ to $+1000 \mathrm{~mm}^{2}$.

We used a wider cut-off than Batzdorf and Batzdorff (1988) for 'straightness' to reflect the results obtained by observation alone.

Statistics. Data were manipulated on a main-frame computer by standard statistical packages (Minitab and SPSS). The significance of any difference in prevalence of loss of cervical lordosis between the groups was calculated from a standardised normal deviate using a pooled estimate of variance for the difference between any two groups (Armitage and Berry 1987). We then used the presence or absence of a straight cervical spine as the dependent variable to perform logistic



Fig. 5

Method used to calculate spinal curvature. The line $\mathrm{AB}$ is drawn from the posterior inferior corner of $\mathrm{C} 2$ to that of C7. The perpendicular distances $\mathrm{d} 1$ to $\mathrm{d} 4 \mathrm{from} \mathrm{AB}$ to the posterior inferior corners of $\mathrm{C} 3$ to $\mathrm{C} 6$ are measured to calculate the arc and the shaded area, bounded by straight line $A B$ and the arc, is calculated.

regression using age, sex and origin of radiograph as independent variables.

\section{RESULTS}

We were able to identify and read 83 'acute' films, 83 'chronic' films and 80 'normal' films from the ARC Unit. 
Table I. Details of the study groups

\begin{tabular}{|c|c|c|c|}
\hline \multirow[b]{2}{*}{ Origin } & \multicolumn{2}{|l|}{ Age (yr) } & \multirow{2}{*}{$\begin{array}{l}\text { Sex ratio } \\
(\mathbf{M} / \mathbf{F})\end{array}$} \\
\hline & Median & Range & \\
\hline Accident department $(n=8.3)$ & 30.0 & 16 to 87 & 1.31 \\
\hline $\begin{array}{l}\text { General practitioner referral } \\
(n=83)\end{array}$ & 48.0 & 16 to 87 & 0.7 \\
\hline ARC survey $(n=66)$ & 41.5 & 16 to 89 & 0.94 \\
\hline Total $(n=232)$ & 41.5 & 16 to 89 & 0.93 \\
\hline
\end{tabular}

Table II. Relationship between subjective assessment of curvature and measurement of area in $\mathrm{mm}^{2}$

\begin{tabular}{lllll}
\hline & \multicolumn{2}{l}{ Area } & & \\
\cline { 2 - 5 } $\begin{array}{l}\text { Subjective } \\
\text { assessment }\end{array}$ & $\begin{array}{l}\mathbf{5 0 0} \text { to }-100 \\
\text { Kyphosis }\end{array}$ & $\begin{array}{l}\mathbf{- 9 9} \text { to }+99 \\
\text { Straight }\end{array}$ & $\begin{array}{l}+100 \text { to }+499 \\
\text { Normal }\end{array}$ & $\begin{array}{l}+500 \text { to }+1000 \\
\text { Hyperiordotic }\end{array}$ \\
\hline Kyphosis $(n=44)$ & 32 & 11 & 1 & 0 \\
Straight $(n=37)$ & 1 & 31 & 5 & 0 \\
Low straight $(n=20)$ & 0 & 9 & 11 & 0 \\
Normal $(n=121)$ & 0 & 12 & 102 & 7 \\
All $(n=222)$ & 33 & 63 & 119 & 7 \\
\hline
\end{tabular}

Table III. Relationship between origin and measured curvature by numbers of subjects (percentage)

\begin{tabular}{lllll}
\hline & \multicolumn{3}{l}{ Curvature (by area) } \\
\cline { 2 - 5 } Origin & Kyphosis & Straight & Normal & Hyperlordotic \\
\hline $\begin{array}{l}\text { Accident department } \\
(\mathrm{n}=78)\end{array}$ & $7(9)$ & $15(19)$ & $51(65)$ & $5(6)$ \\
$\begin{array}{l}\text { General practitioner } \\
\text { referral }(\mathrm{n}=78)\end{array}$ & $3(4)$ & $20(26)$ & $54(69)$ & $1(l)$ \\
ARC survey $(\mathrm{n}=66)$ & $23(35)$ & $28(42)$ & $14(21)$ & $1(2)$ \\
\hline
\end{tabular}

Fourteen of the films from the ARC Unit were discarded because of their poor quality or because $\mathrm{C} 7$ was not visible, leaving 66 . The median age and sex ratio of each group are given in Table $\mathrm{I}$.

We were unable to calculate the area of the cervical curvature in five films from each of the 'acute' and 'chronic' groups leaving groups of 78,78 and 66 . Table II compares the observers' assessment and the results of area measurement. There is reasonable agreement between the subjective and objective results, but 12 of the radiographs thought to be kyphotic on observation were categorised as either straight $(n=11)$ or normal $(n=1)$ by calculation and 20 of the radiographs considered to be in the 'low straight' category were measured as either straight $(n=9)$ or normal $(n=11)$.

The results for the objective data are given in Table III. There was virtually no difference between 'acute' films and 'chronic' films, with a non-significant difference in prevalence of 'straightness' between the two groups (difference $+6.4 \%$, $95 \%$ confidence interval $-6.4 \%$ to $+19.3 \%$ ). The odds ratio for loss of lordosis in the 'acute' group was 0.69
Table IV. Results of logistic regression analysis (see text for details)

\begin{tabular}{llllll}
\hline & \multicolumn{2}{c}{$\begin{array}{l}\text { Standard } \\
\text { error }\end{array}$} & Significance & Odds ratio & $\begin{array}{l}\text { 95\% confidence } \\
\text { interval }\end{array}$ \\
\hline Sex & 1.0334 & 0.4253 & $\mathrm{p}=0.01$ & 2.81 & 1.23 to 6.44 \\
Origin & -0.5855 & 0.4730 & $\mathrm{p}=0.21$ & 0.56 & 0.22 to 1.41 \\
Age & -0.3868 & 0.2231 & $\mathrm{p}=0.08$ & 0.68 & 0.44 to 1.05 \\
Constant & -0.7182 & 0.7177 & $\mathrm{p}=0.32$ & & \\
\hline
\end{tabular}
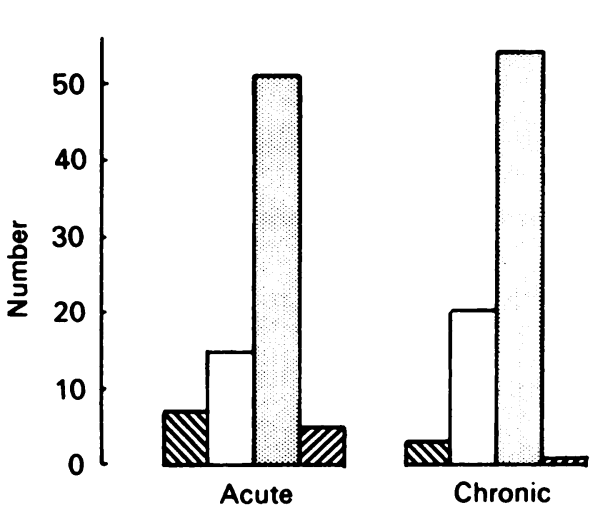

Kyphosis
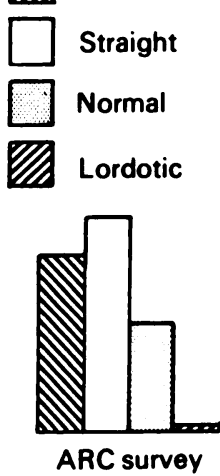

Fig. 6

Histogram illustrating the relationship between the origin of the film and cervical curvature.

(95\% Cl 0.32 to 1.47$)$. The 'normal' group showed a clear difference from the others: many more spines were kyphotic or straight. We did not make statistical comparison with the other groups because of uncertainty about the technique used to obtain these radiographs, a problem which we had not anticipated at the start of our study.

We performed logistic regression analysis using loss of cervical lordosis (straight spine) as the dependent variable, and age group, sex and origin of the films as the independent variables. Age was coded into four groups, origin into two (acute and chronic). The results (Table IV) show that sex was the only significant factor. Even allowing for age, females were 2.5 times more likely to show a straight cervical spine.

\section{DISCUSSION}

We found no difference in the prevalence of loss of cervical lordosis between films of patients with acute neck pain presenting to an accident department, and those from patients with more chronic symptoms referred by general practitioners. This result suggested that loss of cervical lordosis might be due merely to the variations in radiographic positioning. Two of the authors (PSH, PFE), therefore, had screening of their own cervical spines and found that a straight appearance could be readily achieved in a neck position compatible with that recommended by textbooks of radiography.

At first sight, the films from the ARC survey appeared 
to provide an ideal normal control group, but the high proportion which showed a flexed or straight cervical spine (Fig. 6) suggests that a different technique had been used to obtain these radiographs. Review of earlier editions of the standard radiography text by Clark showed that the 1964 edition advised that the lateral cervical spine be radiographed in extension (Clarke 1964); the 1986 edition (Swallow et al 1986) suggests that the jaw should be slightly raised, to take the angle of the mandible away from the atlanto-axial joint. This does not explain why so many of the ARC survey films had been taken in a flexed position.

Our results suggest, though not conclusively, that loss of cervical lordosis is not uniquely associated with acute neck pain and may well result from the radiographer's positioning of patients with a flexible spine. Fullenlove and Williams (1957), investigating low back pain, found loss of lumbar lordosis in $22 \%$ of normal asymptomatic subjects. We conclude therefore that muscle spasm cannot be inferred when loss of lordosis is shown.
We wish to acknowledge the help and co-operation given by $\operatorname{Dr} \mathrm{A}$. Silman, Dr P. Croft and the staff of the ARC Epidemiology Unit, Manchester. We would also like to thank Mrs B. Dibb for secretarial help and Dr K. Simkins whose original question led to the investigation.

No benefits in any form have been received or will be received from a commercial party related directly or indirectly to the subject of this article.

\section{REFERENCES}

Armitage P, Berry G. Statistical methods in medical research. Second ed. Oxford: Blackwell Scientific, 1987.

Batzdorf U, Batzdorff A. Analysis of cervical spine curvature in patients with cervical spondylosis. Neurosurgery 1988; 22:827-36.

Clark KC. Positioning in radiography. Eighth ed. London: William Heinemann, 1964.

Cyriax J. Diagnosis of soft-tissue lesions. Textbook of orthopaedic medicine. Vol. 1. Seventh ed. London, etc: Macmillan, 1978.

Fullenlove TM, Williams AJ. Comparative roentgen findings in symptomatic and asymptomatic backs. Am J Radiology 1957; 68:572-4.

Lawrence JS. Disc degeneration: its frequency and relationship to symptoms. Ann Rheum Dis 1969; 28:121-38.

Swallow RA, Naylor E, Roebuck EJ, Whitely AS, eds. Clark's positioning in radiography. Eleventh ed. London: William Heinemann, 1986. 